\title{
Ameliorative role of melissa officinalis against hepatorenal toxicities of organophosphorus malathion in male rats
}

\begin{abstract}
It has been confirmed that organophosphorus compounds OP altered glucose homeostasis Considerable experimental and clinical evidences have contributed the beneficial effects of antioxidant compounds in plant extract on hepatorenal toxicity. The aim of this study was to evaluate whether Melissa officinalis extract, was able to ameliorative hepatorenal injury induced by organophosphorus Malathion. Malathion at $27 \mathrm{mg} / \mathrm{kg}$ bw was administered to rats alone or in combination with Melissa officinalis extract at $200 \mathrm{mg} / \mathrm{kg}$ bw. Malathion decreases feed intake and body weight as well as liver and kidneys weight. Moreover, Malathion increases the levels of various serum marker enzymes AST, ALT and ALP. A significant increase in the level of serum urea, uric acid and creatinine in response to ML treatment. As well as ML induced increase in MDA in liver and kidneys while induced decreases in the activities of SOD, GPx and CAT. Co-administration of malathion with Melissa officinalis extract resulted in restoration of all tested parameter. These results may be due to the significant increase recorded in acetylcholine esterase (Ach E) activity invivo after co administration of malathion and Melissa officinalis extract. In histological study of liver and kidney, Malathion induced damage in liver and kidneys. However, MO administration to ML-treated animals resulted in overall improvement in liver and kidneys damage, emphasizing its antioxidant role. In light of the available data, it can deduce that ML-induced lipid peroxidation, oxidative stress, liver and kidneys damage rats, and conjoint supplementation of MO has resulted in pronounced ameliorating effect in all tested parameter and histological picture of liver and kidney.
\end{abstract}

Volume I Issue 3 - 2015

\author{
Mohamed M Sief,' Farouk A Khali,', Assem \\ A K Abou Arab,' Mahmoud A Abou Donia,' \\ Ahmed M El-Sherbiny, ${ }^{2}$ Sherif R Mohamed' \\ 'Department of Food Toxicology and Contaminants, National \\ Research Center, Egypt \\ ${ }^{2}$ Department of Animal Physiology,Ain-Shams University, Egypt
}

Correspondence: Mohamed M Sief, Department of Food Toxicology and Contaminants, National Research Center, Egypt, Tel 20128I052247, Email seif.eg@gmail.com

Received: March 05, 20I5 | Published: August 28, 2015
Abbreviations: OP, organophosphorus; AST, aspartate aminotransferase; ALT, alanine transaminase; ALP, alkaline phosphatase; SOD, superoxide dismutase; GPx, glutathione peroxidase; AchE, acetylcholine esterase; ROS, reactive oxygen species; LPO, lipid peroxidation; TBARS, thio barbituric acid reactive substances; CAT, catalase; MDA, malon di aldehyde

\section{Introduction}

The pollution of the environment plays a crucial role in the occurrence of many diseases affecting plants, animals and humans. One of the main factors causing pollution of the environment is the irrational use of organophosphorus pesticides. ${ }^{1}$ The World Health Organization estimated that the incidence of pesticide poisoning in developing countries has doubled between 1987 and $1997 .{ }^{2}$ Organophosphorus insecticides are very toxic compounds, intensively used in agriculture. Their existence in the environment is very harmful to human health as they irreversibly inhibit the catalytic active sites of AchE, an essential enzyme that permits the transmission of electric signals in the nervous system of most animal beings.

The OP compound malathion (S-1, 2(bis ethoxycarbonyl) ethyl O, O dimethyl phosphorodithioate) is used extensively throughout the world, especially in developing countries, to control major arthropods in public health programs, animal ectoparasites, human head and body lice, household insects and to protect grain in storage. ${ }^{3}$

The toxicity of OP agents may be due, at least in part, to the formation of reactive oxygen species (ROS), leading to lipid peroxidation (LPO), which is generally assessed by an increase in the levels of thio barbituric acid reactive substances (TBARS). ${ }^{4}$ In addition, malathion is a lipophilic substance; it may enhance LPO by directly interacting with the cellular plasma membrane. It is evident that LPO is accompanied by an alteration (inhibition or activation) in the antioxidant defence systemin different organs following acute, sub chronic and chronic exposure to OP compounds. ${ }^{5}$ Nevertheless, recent evidence suggests that exposure to different stress models and concentrations (acute, repeated and chronic restraint stress) have an important implication in the alteration of the antioxidant defence system. ${ }^{6}$ The liver is the major metabolizing and the most active organ for mediating bio-activation of thiono-organophosphates. ${ }^{7}$ It is considered among the primarily targets for malathion toxicity.

On the same concern kidney was one of the target organs of experimental animals attacked by acute, sub-chronic and chronic exposure to OP. ${ }^{9}$ Besides, it has been postulated that OP produced oxidative stress in different tissues, such as kidney of rats and mice, through the formation of reactive oxygen species (ROS). ${ }^{10}$

Melissa officinalis belongs to the Laminaceae family, being a perennial herb. Preparations derived from the aerial part of $M$. officinalis are often used in folk medicine for the treatment of fevers and colds, indigestion associated with nervous tension, hyperthyroidism, depression, mild insomnia, epilepsy, headaches, toothaches, flatulence, colic, nausea, nervousness, anaemia, vertigo, syncope, malaise, asthma, bronchitis, amenorrhea, cardiac failure, arrhythmias, depression, psychosis, hysteria, ulcers, wounds, among others. ${ }^{11}$ Thus, the present study was designed to investigate of protective effects of Melissa officinalis extract on liver and kidney damage induced by Malathion.

\section{Melissa officinalis L. plant}

Arial parts of $M$. officinalis were obtained from the herbarium, National Research Center, Giza, Egypt. 


\section{Methods}

\section{Preparation of Melissa officinalis extract}

The dried arial parts powder of M. officinalis L. $(100 \mathrm{~g})$ was soaked at room temperature in $1000 \mathrm{ml}(70 \%$ ethanol $)$ and extracted for 1 week. On the seventh day, the ethanolic extract was stirred for $12 \mathrm{~h}$ and filtered through a Whatman No.1 filter paper, and then solvent was fully evaporated with a rotary evaporator (Panchun Scientific Co.) at $35^{\circ} \mathrm{C}$. The ethanolic extract was freeze dried. The freeze dried extract was dissolved in corn oil $(10 \mathrm{~g} / \mathrm{L})$, and the dose adjusted at $200 \mathrm{mg} / \mathrm{kg}$ bw.

\section{Experimental groups}

After an acclimatization period of 1 week, animals were equally divided into four groups ( 8 rats in each) and housed in filter top polycarbonate cages. Animals were segregated into four groups each group comprised eight animals and treated daily for 90 consecutive days. The selected dose of the insecticide was based on Kalender et al. ${ }^{12}$ in which $1 / 50 \mathrm{LD}_{50}$ of $\mathrm{ML}$ induced biochemical alterations in rats without morbidity.

\section{Body weight, Feed intake, and blood collection}

Body weight changes of all rats were recorded daily during the experimental period (90 days), as well as daily feed intake was recorded. At the end of this period, blood samples were collected from the animals under ether anaesthesia by puncturing the retro-orbital venous plexus with a fine sterilized glass capillary. Blood was left for 20min at room temperature, then centrifuged at 3000rpm under cooling for 10min using Hereaeus Labofuge 400R, Kendro Laboratory Products $\mathrm{GmbH}$, Germany, to separate the sera. The sera was kept in a deep freezer $\left(-20^{\circ} \mathrm{C}\right)$ until analysis within 1 week.

\section{Organs weight}

After blood collection, rats were sacrificed by cervical dislocation. Liver and kidneys were quickly removed and weighed individually.

\section{Biochemical estimations}

\section{Biochemical parameter in serum}

The sera was used for the determination of the Acetylcolinestrase (AchE) Alanineaminotransaminase (ALT), Aspartateaminotransaminase (AST), Alkaline phosphatase (ALP), urea, uric acid, and creatinine according Reitman et al., ${ }^{13}$ Belfield et al., ${ }^{14}$ Blass et al. ${ }^{15}$ respectively.

\section{Antioxidant enzymes in liver and kidneys homogenates}

After the collection of blood samples, all animals were sacrificed and samples from hepatic and renal tissues (approximately $0.05-0.1 \mathrm{~g}$ ) were homogenized in phosphate buffer ( $\mathrm{pH} 7.4)$ to give $20 \% \mathrm{w} / \mathrm{v}$ homogenate. ${ }^{16}$ This homogenate was centrifuged at $1700 \mathrm{rpm}$ and $4{ }^{\circ} \mathrm{C}$ for $10 \mathrm{~min}$; the supernatant was stored at $-20^{\circ} \mathrm{C}$ until analysis. This supernatant $(20 \%)$ was used for the determination of the following:

Malondialdehyde (MDA) measurement: The liver and kidneys malondialdehyde concentrations, a lipid peroxidation index, were determined spectrophotometrically according to Draper et al. ${ }^{17}$ Briefly, an aliquot of liver and kidneys extract supernatant was mixed with $1 \mathrm{ml}$ of $5 \%$ trichloroacetic acid and centrifuged at $2500 \mathrm{~g}$ for $10 \mathrm{~min}$. An amount of $1 \mathrm{ml}$ of thiobarbituric acid reagent $(0.67 \%)$ was added to $500 \mathrm{ml}$ of supernatant and heated at $90^{\circ} \mathrm{C}$ for $15 \mathrm{~min}$. The mixture was then cooled and measured for absorbance at $532 \mathrm{~nm}$ using a spectrophotometer (JenwayUV-6305, Essex, England). The malondialdehyde values were calculated using 1, 1, 3, 3-tetraethoxypropane as standard and expressed as nmoles of malondialdehyde/g of liver.

Superoxide dismutase (SOD) activity: Superoxide dismutase (SOD) activity in liver and kidneys supernatant was estimated according to Marklund et al. ${ }^{18}$ by assaying the auto oxidation and illumination of pyrogallol at $440 \mathrm{~nm}$ for $3 \mathrm{~min}$. One unit of SOD activity was calculated as the amount of protein that caused $50 \%$ pyrogallol auto oxidation inhibition. The SOD activity was expressed as U/mg protein.

Glutathione peroxidase (GPx): Glutathione peroxidase (GPx) activity was performed using $\mathrm{H}_{2} \mathrm{O}_{2}$ as substrate according to Paglia et al. ${ }^{19}$ The reaction was monitored indirectly as the oxidation rate of NADPH at $240 \mathrm{~nm}$ for $3 \mathrm{~min}$. The enzyme activity was expressed as $\mathrm{nmol} / \mathrm{mg}$ protein.

Catalase (CAT): Catalase (CAT) activity was assayed as described by Aebi, ${ }^{20}$ by assaying the hydrolysis of $\mathrm{H}_{2} \mathrm{O}_{2}$ and the resulting decrease in absorbance at $240 \mathrm{~nm}$ over a $3 \mathrm{~min}$ at $25^{\circ} \mathrm{C}$. CAT activity was expressed as $\mathrm{nmol} / \mathrm{mg}$ protein.

\section{Histological studies}

Samples from liver and kidneys, intended for histological examination by light microscopy, were immediately fixed in $10 \%$ of formalin and processed in a series of graded ethanol solutions. They were then embedded in paraffin, serially sectioned at $6 \mathrm{~mm}$ and stained with hematoxylin-eosin. Two slides were prepared from each tissue. All sections were evaluated for the degree of organs injury.

\section{Statistical analysis}

Data were analyzed as a completely randomized design using the linear model procedure of SAS (1986). Means were statistically compared using least significant difference (LSD) test at $\mathrm{p} \leq 0.05$ significance level.

\section{Results}

\section{The effects of ML on general rats health}

Death was not observed in any experimental group during the treatment period (90 days). However, in ML treated group, few clinical signs such as reduced activity, increasing weakness, slight vomiting and hair loss were observed.

\section{Body weight, Feed intake and weight of liver and kidney}

The results indicated that animals treated with ML for 90days showed a significant decrease in body weight, food intake, liver and kidney weights compared to the control group. Animals treated with MO plus ML showed a significant improvement in bodyweight, food intake, liver and kidney weighs (Table 1). ML treatment also decreased the absolute and liver and kidney weight. However, the animals treated with ML plus Mo was restored to normal values compared to controls (Table 1). 
Table I Initial body weights, final body weights, body weight gain, liver and kidney weights and daily feed consumption in adult male rats in different groups during 90 days

\begin{tabular}{lllll}
\hline Parameters & Control & MO & ML & MO + ML \\
\hline Initial Body Weights $(g)$ & $130 \pm 0.21^{\mathrm{a}}$ & $131 \pm 0.18^{\mathrm{a}}$ & $131 \pm 0.20^{\mathrm{a}}$ & $130 \pm 0.18^{\mathrm{a}}$ \\
Final Body Weights $(\mathrm{g})$ & $236.2 \pm 0.2^{\mathrm{a}}$ & $233.9 \pm 0.23^{\mathrm{a}}$ & $180.9 \pm 0.52^{\mathrm{b}}$ & $230.4 \pm 0.43^{\mathrm{a}}$ \\
Weight Gain (\%) & $81.6 \pm 0.24^{\mathrm{a}}$ & $78.5 \pm 0.34^{\mathrm{a}}$ & $38.0 \pm 0.43^{\mathrm{b}}$ & $82.0 \pm 0.42^{\mathrm{a}}$ \\
Initial Feed Intake (g/day/rat) & $18.0 \pm 0.1^{\mathrm{a}}$ & $17.0 \pm 0.2^{\mathrm{a}}$ & $15.4 \pm 0.24^{\mathrm{b}}$ & $17.0 \pm 0.1^{\mathrm{a}}$ \\
Final Feed Intake (g/day/rat) & $27.32 \pm 0.24^{\mathrm{a}}$ & $26.18 \pm 0.23^{\mathrm{a}}$ & $10.42 \pm 0.35^{\mathrm{b}}$ & $25.0 \pm 0.5^{\mathrm{a}}$ \\
Liver Weights (g) & $6.34 \pm 0.07^{\mathrm{a}}$ & $6.2 \pm 0.06^{\mathrm{a}}$ & $4.14 \pm 0.24^{\mathrm{b}}$ & $5.72 \pm 0.27^{\mathrm{a}}$ \\
kidney Weights $(\mathrm{g})$ & $1.58 \pm 0.02^{\mathrm{a}}$ & $1.61 \pm 0.04^{\mathrm{a}}$ & $0.77 \pm 0.02^{\mathrm{b}}$ & $1.32 \pm 0.02^{\mathrm{a}}$
\end{tabular}

Within each row, means superscribed with different letters are significantly different $(\mathrm{P} \leq 0.05)$; control= untreated group, $M O=M e l i s s a$ officinalis; $M L=M a l a t h i o n ;$ $\mathrm{MO}+\mathrm{ML}=$ Melissa officinalis + Malathion.

\section{Biochemical parameter in serum}

Animals treated with ML showed a significant increase in serum ALT, AST, ALP, creatinine, urea and uric acid while showed significant decrease in acetylcholinestrase activity (Table 2). However, animals treated with Melissa officinalis alone did not show a significant change in all parameter tested. Animals treated with ML showed a significant improvement in all parameter tested compared with control croup. Whereas animal treated with Mo plus Ml did not show a significant improvement in all parameter compared to control (Table 2).

Table 2 Effect of Melissa officinalis on serum biochemical parameter in male rats treated with Malathion $(27 \mathrm{mg} / \mathrm{kg}$ bw) for 12 weeks

\begin{tabular}{|c|c|c|c|c|c|c|c|}
\hline $\begin{array}{l}\text { Parameterl } \\
\text { Groups }\end{array}$ & AChE (U/L) & ALT (IU/L) & AST (IU/L) & ALP (IU/L) & Creatinine $(\mathrm{mg} / \mathrm{dl})$ & Uric acid (mg/dl) & Urea (mg/dl) \\
\hline Control & $75.24 \pm 0.62^{\mathrm{a}}$ & $38.58 \pm 0.9^{a}$ & $69.5 \pm 1.6^{\mathrm{a}}$ & $56.14 \pm 0.95^{a}$ & $0.73 \pm 0.0 \mathrm{I}^{\mathrm{a}}$ & $1.06 \pm 0.04^{\mathrm{a}}$ & $3.46 \pm 0.1^{\mathrm{a}}$ \\
\hline MO & $73.23 \pm 0.63^{\mathrm{a}}$ & $36.06 \pm 0.5^{a}$ & $67.7 \pm 1.3^{\mathrm{a}}$ & $49.9 \pm 0.47^{a}$ & $0.77 \pm 0.0 \mathrm{I}^{\mathrm{a}}$ & $1.08 \pm 0.05^{a}$ & $3.7 I \pm 0.07^{a}$ \\
\hline$M L$ & $45.22 \pm 0.87^{b}$ & $89.90 \pm 1.9^{b}$ & $120.9 \pm 1.5^{b}$ & $171.8 \pm 2.1^{b}$ & $1.55 \pm 0.02^{b}$ & $1.59 \pm 0.02^{b}$ & $7.01 \pm 0.26^{b}$ \\
\hline $\mathrm{MO}+\mathrm{ML}$ & $70.82 \pm 0.53^{\mathrm{a}}$ & $53.33 \pm 1.2^{\mathrm{a}}$ & $78.6 \pm 1.2^{\mathrm{a}}$ & $71.40 \pm 1.9^{a}$ & $0.83 \pm 0.0 \mathrm{I}^{\mathrm{a}}$ & $1.12 \pm 0.03^{\mathrm{a}}$ & $4.04 \pm 0.22^{\mathrm{a}}$ \\
\hline
\end{tabular}

Within each column, means superscribed with different letters are significantly different $(P \leq 0.05)$;

AchE =Acetylcholinestrase $; \mathrm{ALT}=$ Alanineaminotransaminase $; \mathrm{AST}=$ Aspartateaminotransaminase; $\mathrm{ALP}=\mathrm{Alkaline}$ Phosphatase.

Antioxidant enzymes in liver and kidneys homogenates

The results indicated that in the liver and kidneys homogenates of ML-treated rats, superoxide dismutase (SOD), catalase (CAT) and glutathione peroxidase (GPx) activities had a significant decrease, when compared to controls (Table 3). While treatment with ML resulted in a significant increase in liver and kidneys MDA (Table 3). Treatment with $\mathrm{MO}$ alone resulted in a non significant changes in all parameters tested liver and kidneys compared control. Whereas animals treated with ML showed a significant improvements in all parameter tested (Table 3).

Table 3 Effect of Melissa officinalis on MDA, SOD, CAT and GPx in male rats treated with Malathion $(27 \mathrm{mg} / \mathrm{kgbw})$ for 12 weeks

\begin{tabular}{lllllllll}
\hline $\begin{array}{l}\text { Parameter } \\
\text { Groups }\end{array}$ & MDA (nmol/mg Protein) & \multicolumn{2}{l}{ SOD (U/mg Protein) } & \multicolumn{2}{l}{ CAT (m mol/mg Protein) } & \multicolumn{2}{l}{ GPx (nmol/mg Protein) } \\
\hline & Liver & Kidneys & Liver & Kidneys & Liver & Kidneys & Liver & Kidneys \\
\hline Control & $72.33 \pm 0.4 \mathrm{a}$ & $9.9 \pm 0.62^{\mathrm{a}}$ & $14.68 \pm 0.3^{\mathrm{a}}$ & $11.28 \pm 0.4^{\mathrm{a}}$ & $20.33 \pm 0.5^{\mathrm{a}}$ & $43.33 \pm 0.73^{\mathrm{a}}$ & $8.33 \pm 0.43^{\mathrm{a}}$ & $5.06 \pm 0.09^{\mathrm{a}}$ \\
MO & $73.94 \pm 0.21^{\mathrm{a}}$ & $10.8 \pm 0.64^{\mathrm{a}}$ & $15.71 \pm 0.4^{\mathrm{a}}$ & $11.9 \pm 0.15^{\mathrm{a}}$ & $21.65 \pm 0.36^{\mathrm{a}}$ & $44.46 \pm 0.35^{\mathrm{a}}$ & $7.83 \pm 0.44^{\mathrm{a}}$ & $5.27 \pm 0.12^{\mathrm{a}}$ \\
ML & $127.2 \pm 1.6^{\mathrm{b}}$ & $68.5 \pm 1.4^{\mathrm{b}}$ & $8.02 \pm 0.6^{\mathrm{b}}$ & $8.4 \pm 0.25^{\mathrm{b}}$ & $11.01 \pm 0.61^{\mathrm{b}}$ & $29.21 \pm 0.42^{\mathrm{b}}$ & $5.29 \pm 0.46^{\mathrm{b}}$ & $2.71 \pm 0.31^{\mathrm{b}}$ \\
MO+ML & $81.2 \pm 1.9^{\mathrm{ab}}$ & $16.7 \pm 1.7^{\mathrm{a}}$ & $12.69 \pm 0.6^{\mathrm{a}}$ & $11.5 \pm 0.25^{\mathrm{a}}$ & $19.23 \pm 0.45^{\mathrm{ab}}$ & $41.87 \pm 0.80^{\mathrm{a}}$ & $7.99 \pm 0.04^{\mathrm{a}}$ & $4.32 \pm 0.13^{\mathrm{a}}$ \\
\hline
\end{tabular}

Within each column, means superscribed with different letters are significantly different $(P \leq 0.05)$; MDA= Malondialdehyde; $S O D=$ superoxide dismutase; $C A T=$ catalase; $\mathrm{GPx}=$ glutathione peroxidase.

\section{Histological studies}

Light microscopic examination indicated a normal structure of the liver and kidneys in the controls group, and those treated with $\mathrm{MO}$ alone and MO plus ML (Figure 1A, 1B and 1F), (Figure 2A, 2B and 1D). However, Liver sections of animals treated with ML showed hyperplasia of epithelial lining bile duct and fibroplasia in portal ca- nal (Figure 1C), Kupffer cell activation and focal hepatic necrosis associated with inflammatory cells infiltration (Figure 1D) and focal hepatic necrosis were associated with inflammatory cells infiltration as well as apoptosis of hepatocytes (Figure 1E) in liver. On the other hand, Kidneys sections of animals treated with ML alone showed congestion of glomerular tuft, perivascular oedema associated with inflammatory cells infiltration in kidneys (Figure 2 C), (H \& E X 400). 


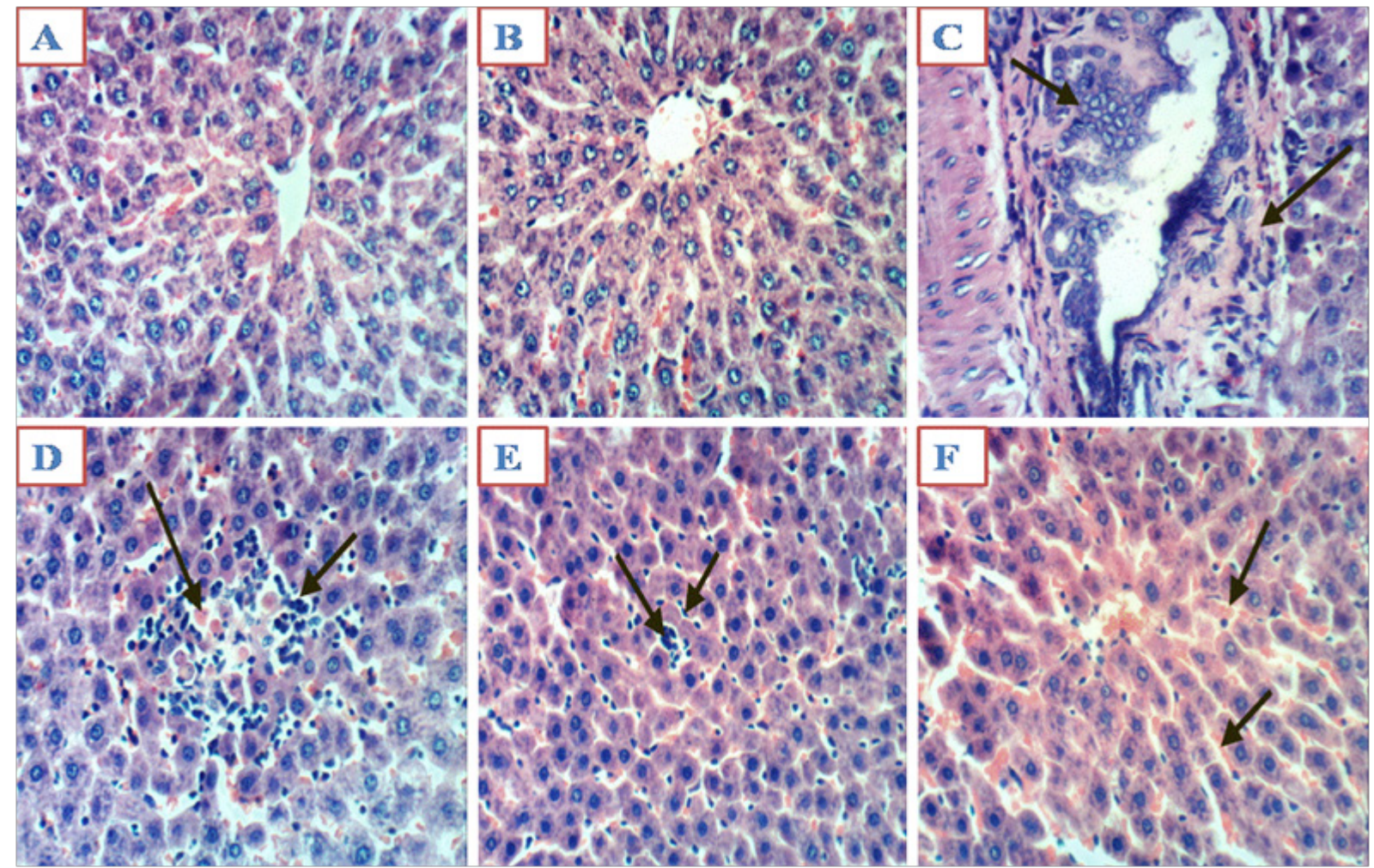

Figure I A) A photomicrograph in liver of control rats showed normal central vein and normal hepatocytes. B) The liver sections in the rats treated with Melissa officinalis extract alone showed normal parenchyma and normal focal aggregation of lymphocytes. C) A section of liver of Malathion group showed hyperplasia of epithelial lining bile duct and fibroplasia in portal triad. D) A section of liver of Malathion group showed focal hepatic necrosis associated with inflammatory cells infiltration as well as apoptosis of hepatocytes. E) A section of liver of Malathion group showed Kupffer cell activation and few leucocytes in hepatic sinusoids. F) A section of liver of rats treated with Malathion plus Melissa officinalis showed slight congestion of hepatic sinusoids (arrow). (H \& E X 400).
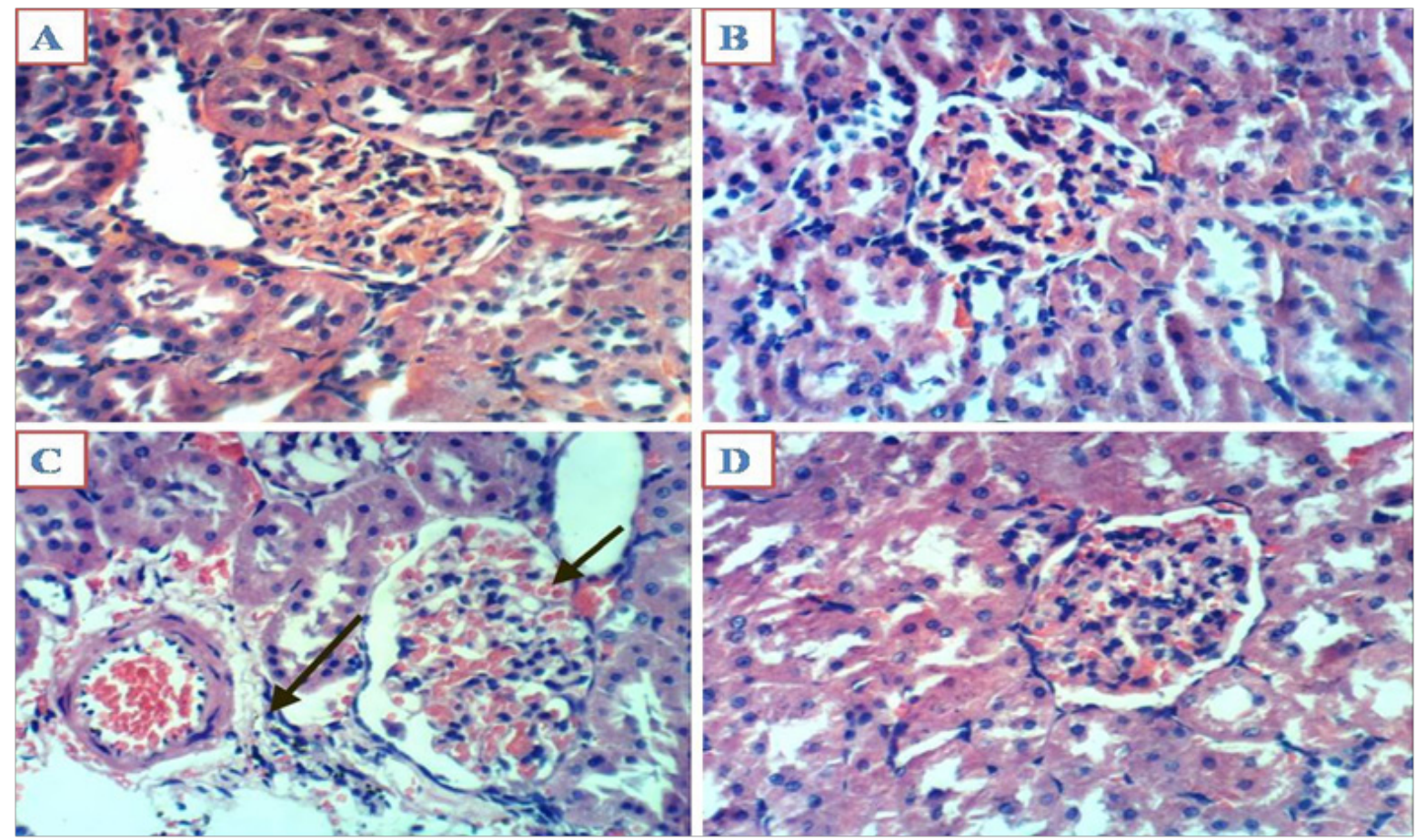

Figure 2 A) A section of Kidney of rats in control group the normal histological structure of renal parenchyma. B) A section of Kidney of rats treated with Melissa officinalis extract alone showed no histopathological changes. C) A section of Kidney of rats treated with Malathion alone showed congestion of glomerular tuft, perivascular oedema associated with few inflammatory cells infiltration (arrows). D) A section of Kidney of rats treated with Melissa officinalis extract plus Malathion showed no histopathological changes (H \& E X 400).

Citation: Sief MM, Khalil FA, Abou-Arab AA, et al.Ameliorative role of melissa officinalis against hepatorenal toxicities of organophosphorus malathion in male rats. MOJ Toxicol. 2015;I(3):I03-109. DOI: 10.15406/mojt.2015.01.00014 


\section{Discussion}

The widespread use of malathion has led to the exposure of animals, birds, and non-target invertebrates to this pesticidal chemical and the contamination of human food sources. ${ }^{21}$ Mammals are likely to be adversely affected by oral, dermal, and inhalation exposure to Malathion. ${ }^{22}$ While the oral $\mathrm{LD}_{50}$ of malathion for male rat is $1350 \mathrm{mg} /$ $\mathrm{kg}$. Malathion is an organophosphorothionate pesticide with relative low toxicity, can be activated by the cytochrome P450 system by oxidative desulfuration to form malaoxon, an effective inhibitor of AchE. ${ }^{23}$

In the present study, we have explored the effects of a sub chronic exposure of malathion at $27 \mathrm{mg} / \mathrm{kg}$ bw $\left(1 / 50\right.$ of the oral $\left.\mathrm{LD}_{50}\right)$ for 90 days on liver and kidneys toxicities in male rats. Present study showed that sub chronic exposure to malathion was able to induce a significant decrease in body weight, food intake, liver and kidney weights in ML-treated group compared control group. This could be due to decreased water and food intake in these animals. Many studies have shown that OP insecticides cause reduction of body weight in experimental animals. ${ }^{24}$

The weight reduction in ML-treated rats may be due to reduced appetite of rats, ${ }^{12}$ a result of choline esterase inhibition ${ }^{24}$ and the toxic effect or hormonal imbalance in any step in the hypothalamohypophysial-testicular axis. ${ }^{25}$

The result of the present study showed a significant increase in serum ALT, AST and ALP in ML-treated animals when compared with another groups. A significant increase in serum activities of AST and ALT considered like markers enzymes of hepatocyte cytolysis. Indeed, AST and ALT are two hepatic enzymes which will be released in blood in the event of cellular destruction proportionally to the intensity of the cellular aggression. ${ }^{26}$ The recorded increase of AST and ALT levels may be due to increased LPO. When the liver cell membrane is damaged, several enzymes located in the hepatocyte cytosol, including, ALT, AST and ALP, are secreted into the blood. ${ }^{27}$ Consequently, these serum enzymes are markers of liver damage. It has been shown that OP insecticides can elevate the enzymatic activities of ALP, ALT, and AST.27 Moreover, malathion raises the ALT and AST levels in rats. ${ }^{28}$ Indeed, we have seen a high positive correlation between serum rates of AST and ALT and hepatic MDA level. This is consistent with the damage to the hepatic tissues in the malathion-treated rats seen by light microscopy.

Like other OP compounds, malathion is known to inhibit AchE..$^{29}$ In this study, we also demonstrated the inhibition of AChE in rat treated with malathion alone versus another groups. Inhibition of AchE by OP leads to an accumulation of acetylcholine and subsequent impairment of numerous body functions. ${ }^{30}$

The present results showed that there was a statistically significant enhance in serum creatinine, urea and acid uric levels. Parameters like urea, uric acid and creatinine levels are significant indicators to evaluate kidney functions. ${ }^{31}$ In context, enhanced urea, uric acid and creatinine concentrations have been used to indicate renal dysfunction. As being major metabolic product of protein metabolism, blood urea nitrogen studied to indicate glomerular damage ${ }^{32}$ Blood urea nitrogen, uric acid and creatinine levels were significantly increased after 12 weeks malathion treatment $(27 \mathrm{mg} / \mathrm{kg}$ bw). Enhanced urea level correlated with elevated protein catabolism and/or the conversion of ammonia to urea as a result of elevated synthesis of arginase enzyme involved in urea production. ${ }^{33}$ Creatinine is an end metabolic product of muscle catabolism and is removed at a constant rate by the kidneys. ${ }^{34}$ The creatinine excretion is dependent on the process of glomerular filtration. The elevated creatinine level shows that damage of the glomerular function and tubular damage. ${ }^{35}$ Uric acid is the major metabolic product of purine nucleotides. ${ }^{36}$ Impairment in kidney function could probably occur via kidney oxidative damage. This compound is the end product of purine catabolism and can reduce oxidative stress by scavenging various ROS. ${ }^{37}$ Antioxidants constitute the foremost defense system that limits the toxicity associated with free radicals. ${ }^{38}$ Moreover, the cellular antioxidant status determines the susceptibility to oxidative damage and is usually altered in response to oxidative stress. Our results indicated that a significant increase of MDA activity and a significant decrease in SOD, GPx and catalase in liver and kidneys of animals treated with ML at end of the experimental period, those results consistent with those reported by Rosety et al. ${ }^{39}$

CAT is a hematin-containing enzyme located in peroxisomes and facilitates the removal of hydrogen peroxide $\left(\mathrm{H}_{2} \mathrm{O}_{2}\right)$, which is metabolized to molecular oxygen $\left(\mathrm{O}_{2}\right)$ and water. Therefore, the SOD-CAT system provides the first defense against oxygen toxicity. CAT activity is directly regulated by the concentration of $\mathrm{H}_{2} \mathrm{O}_{2} \cdot{ }^{40}$ The present results showed that the tendency of CAT was consistent with the changes of SOD activity. This suggested that $\mathrm{H}_{2} \mathrm{O}_{2}$ generated by SOD was removed by CAT directly.

GPx and CAT have complementary roles in $\mathrm{H}_{2} \mathrm{O}_{2}$ detoxification. In the present study, the results showed that GPx activity had a significant decrease under Malathion stress. This suggested that GPx play an important role in detoxifying $\mathrm{H}_{2} \mathrm{O}_{2}$ caused by malathioninduced oxidative stress. The decreased activities of GPx indicate its reduced capacity to scavenge $\mathrm{H}_{2} \mathrm{O}_{2}$ and lipid hydroperoxides. ${ }^{41}$ GPx is a seleno anti peroxidative enzyme that is present both in cytosol and mitochondrial matrix. ${ }^{34}$ The main function of GPx is to reduce hydrogen peroxide. Decreased GPx level was determined in ML-treated rats. ML may inhibit the GPx directly by impairing the functional groups. ${ }^{42}$ Also the reduction in the CAT and GPx activities may occurred as a defence response used against hydrogen peroxide generated by ML. ${ }^{43}$

The elevated level of MDA might be due to enhanced formation of free radicals. Malathion-induced escalation of MDA level could be used as an indicator of malathion damage. Jihen et al., ${ }^{44}$ reported that some antioxidant enzymes, such as SOD, CAT, and GPx, play a crucial role in anti oxidation and elimination of reactive oxygen species. SOD, CAT and GPx activities decreased in various rat tissues mercuric chloride-treated. ${ }^{45} \mathrm{SOD}, \mathrm{CAT}$ and GPx activities decreased in the kidney tissues of ML treated rats. SOD catalyzes the conversion of superoxide anion into hydrogen peroxide. Hydrogen peroxide is converted to water by $\mathrm{CAT} .{ }^{46} \mathrm{CAT}$ is responsible for equilibration the formation of hydrogen peroxide and superoxide radicals. In our study, the inhibition of SOD and CAT activities might be due to overwhelming reactive oxygen species production.

Recently, De CarvalhoI et al., ${ }^{47}$ have demonstrated that $M$. officinalis exhibits antigenotoxic/ antimutagenic properties in mice. So in our work the effect of melissa extract as a main source of antioxidants against malathion hazard in rat testes was studied and found that the $M$. officinalis extract has antioxidant activity agent and could improve the biochemical and histochemical picture of rat testes against toxicity of malathion.

OP insecticides are known to induce various histopathological 
changes in the liver tissues ${ }^{48}$ and indeed we found by light microscopic analyses that malathion-induced hyperplasia of epithelial lining bile duct and fibroplasia in portal triad and Kupffer cell activation and focal hepatic necrosis associated with inflammatory cells infiltration and focal hepatic necrosis associated with inflammatory cells infiltration as well as apoptosis of hepatocytes in Liver sections of animals treated with ML when compared with control group. On the other hand Kidneys sections of animals treated with ML alone showed congestion of glomerular tuft, perivascular oedema associated with inflammatory cells infiltration in kidneys when compared with control group. The sections of liver and kidneys of animal treated with MO or MO plus ML showed improvements in histological picture. The basis of histological changes may be due to increased lipid peroxidation ML induced. These changes harmonize with our biochemical examinations. ${ }^{49}$

In previous study, Seif et al. reported that male rats exposed to malathion for 12 weeks was caused testicular toxicity, and the Melissa officinalis extract posses the protective role against toxicity of malathion on rat testes since it contains the antioxidant components and could improve the sperm counts, motility and morphology. And also protect malathion-exposed rats from the effects of malathion on FSH, LH and testosterone levels.

\section{Conclusion}

The present study showed that ML intoxication caused reactive oxygen species generation which in turn induced histopathological and biochemical alterations in rats liver and kidneys. Administration of Melissa officinalis L. extract proved to be beneficial in attenuating the Malathion induced hepatorenal toxicity

\section{Acknowledgements}

The authors wish to express their appreciation to Prof. Khayria M. Naguib. Head of Mycotoxins Central Lab., National Research Center, Cairo, Egypt for her great supports for this work.

\section{Conflict of interest}

The author declares no conflict of interest.

\section{References}

1. Al-Haj, Nasser M, Anis A. Survey of pesticides used in Qat cultivation in Dhale and Yafe and their adverse effects. J Nat Appl Sci. 2005;9:103110 .

2. WHO. Guidelines for Poison Control. Geneva: WHO in collaboration with UNEP and ILO; 1997. p. 3-10.

3. Maroni M, Colosio C, Ferioli A, et al. Biological monitoring of pesticide exposure: a review. Introduction. Toxicology. 2000;143(1):1-118.

4. Verma RS, Srivastava N. Chlorpyrifos induced alterations in levels of thiobarbituric acid reactive substances and glutathione in rat brain. Indian J Exp Biol. 2001;39(2):174-177.

5. Fortunato JJ, Feier G, Vitali AM, et al. Malathion-induced oxidative stress in rat brain regions. Neurochem Res. 2006;31(5):671-678

6. Sahin E, Gumuslu S, Ozturk O, et al. Marked changes in erythrocyte antioxidants and lipid peroxidation levels of rats exposed to acute, repeated and chronic restraint stress. Pharmazie. 2004;59(12):961-964.

7. Neal RA. A comparison of the in vitro metabolism of parathion in the lung and liver of the rabbit. Toxicol Appl Pharmacol. 1972;23(1):123130 .
8. Yang MC, McLean AJ, Rivory LP, et al. Hepatic disposition of neurotoxins and pesticides. Pharmacol Toxicol. 2000;87(6):286-291.

9. Assini FL, Zanette KD, Brocardo PS, et al. Behavioral effects and ChE measures after acute and repeated administration of malathion in rats. Environ Toxicol Pharmacol. 2005;20(3):443-449.

10. Savolainen K. Understanding the toxic actions of organophosphates In: Krieger RI, editor. Handbook of Pesticide Toxicology. USA: Academic Press; 2001. p. 1013-1041.

11. Schemann M, Michel K, Zeller F, et al. Region-specific effects of STW 5 (Iberogast) and its components in gastric fundus, corpus and antrum. Phytomedicine. 2006;13 Suppl:90-99.

12. Kalendera S, Kalenderb Y, Durakc D, et al. Methyl parathion induced nephrotoxicity in male rats and protective role of vitamins $\mathrm{C}$ and $\mathrm{E}$. Pesticide Biochemistry and Physiology. 2007;88(2):213-218.

13. Reitman S, Frankel S. Colorimetric method for aspartate and alanine tranferases. Am J Clin Pathol. 1957;28:56-63.

14. Belfeild A, Golderge DM. Normal ranges and diagnostic value of serum nucleotidase and alkaline Phosphatase activities in infancy. Arch Dis Child. 1971;46(250):842-846.

15. Blass KG, Thibert RJ, Lam LK. A study of the mechanism of the Jaffe reaction. Z Klin Chem Klin Biochem. 1974;12:336-343.

16. Lin CC, Hsu YF, Lin TC, et al. Antioxidant and hepatoprotective activity of punicalagin and punicalin on carbon tetrachloride-induced liver damage in rats. J Pharm Pharmacol. 1998;50(7):789-794.

17. Draper HH, Hadley M. Malondialdehyde determination as index of lipid peroxidation. Methods Enzymol. 1990;186:421-431.

18. Marklund S, Marklund G. Involvement of the superoxide anion radical in the autoxidation of pyrogallol and a convenient assay for superoxide dismutase. Eur J Biochem. 1974;47(3):469-474.

19. Paglia DE, Valentine WN. Studies on the quantitative and qualitative characterization of erythrocytes glutathione peroxidase. $J$ Lab Clin Med. 1967;70(1):158-168.

20. Aebi H. Catalase in-vitro. Methods Enzymol. 1984;105:121-126.

21. Sodhi S, Sharma A, Brar APS, et al. Effect of a tocoferol and selenium on antioxidant status, lipid peroxidation and hepatopathy induced by malathion in chicks. Pesticide Biochemistry and Physiology. 2008;90(2):82-86.

22. Lasram MM, Annabi AB, El Elj N, et al. Metabolic disorders of acute exposure to malathion in adult Wistar rats. $J$ Hazard Mater. 2009;163(2-3):1052-1055.

23. Buratti FM, DAniello A, Volpe MT, et al. Malathion bioactivation in the human liver: the contribution of different cytochrome P450 isoforms. Drug Metab Dispos. 2005;33(3):295-302.

24. Hariri AR, Manuck SB, Ferrell RE, et al. Multilocus Genetic Profile for Dopamine Signaling Predicts Ventral Striatum Reactivity. Neuropsychopharmacology. 2011;36(9):1940-1947.

25. Diricana EK, Kalender Y. Dichlorvos-induced testicular toxicity in male rats and the protective role of vitamins C and E. Exp Toxicol Pathol. 2011;64(7-8):821-830.

26. Vinogradova LF, Mirzoian ZA, Kharlitskaia EV, et al. Experimental antioxidant therapy in toxic liver damage from $\mathrm{CCl} 4$ and chloxyl. Patol Fiziol Eksp Ter. 1989;4:52-56.

27. Ncibi S, Othman M, Akacha A, et al. Opuntia ficus indica extract protects against chlorpyrifos-induced damage on mice liver. Food Chem Toxicol. 2008;46(2):797-802. 
28. Rezg R, Mornagui B, El-Fazaa S, et al. Biochemical evaluation of hepatic damage in sub chronic exposure to malathion in rats:effect on superoxide dismutase and catalase activities using native PAGE. $C R$ Biol. 2008;331(9):655-662.

29. Guez D, Zhang SW, Srinivasan MV. Methyl parathion modifies foraging behavior in honeybees (Apis mellifera). Ecotoxicology. $2005 ; 14(4): 431-437$

30. Bartling A, Worek F, Szinicz L, et al. Enzyme-kinetic investigation of different sarin analogues reacting with human acetylcholinesterase and butyrylcholinesterase. Toxicology. 2007;233(1-3):166-172.

31. Al-Attar AM, Al-Taisan WA. Preventive effects of black seed (Nigella sativa) extract on Sprague Dawley rats exposed to diazinon. Aust $J$ Basic Appl Sci. 2010;4:957-968.

32. Yang $\mathrm{H}, \mathrm{Xu} \mathrm{Z}$, Liu $\mathrm{W}$, et al. The protective role of procyanidins and lycopene against mercuric chloride renal damage in rats. Biomed Environ Sci. 2011;24(5):550-559.

33. Renugadevi J, Prabu SM. Quercetin protects against oxidative stressrelated renal dysfunction by cadmium in rats. Exp Toxicol Pathol. 2010;62(5):471-481.

34. Vijayaprakasha S, Langeswaranb K, Gowtham Kumarc S, et al Nephro-protective significance of kaempferol on mercuric chloride induced toxicity in Wistar albino rats. Biomedicine \& Aging Pathology. 2013;3(3):119-124.

35. Soudani N, Sefi M, Amara IB, et al. Protective effects of selenium (Se) on chromium (VI) induced nephrotoxicity in adult rats. Ecotoxicol Environ Safe. 2010;73(4):671-678

36. Davies DM. Text Book of Adverse Drug Reductions. 4th ed. Oxford Oxford Medical Publications; 1991

37. Ranjbar A, Pasalar P, Abdollahi M. Induction of oxidative stress and acetylcholine esterase inhibition in organophosphorous pesticide manufacturing workers. Hum Exp Toxicol. 2002;21(4):179-182.

38. Pincemail J, Bonjean $\mathrm{K}$, Cayeux $\mathrm{K}$, et al. Mecanismes physiolo giques de la defense antioxydante. Nutrition Clinique et Métabolisme. 2002;16(4):233-239.
39. Rosety M, Rosety Rodriguez M, Ordonez FJ, et al. Time course variations of antioxidant enzyme activities and histopathology of gilthead seabream gills exposed to malathion. Histol Histopathol. 2005;20(4):1017-1020

40. Fornazier RF, Ferreira RR, Vitória AP, et al. Effects of cadmium on antioxidant enzyme activities in sugar cane. Biologia Plantarum. 2002;45(1):91-97.

41. Lenartova V, Holovska K, Pedrajas JR, et al. Antioxidant and detoxifying fish enzymes as biomarkers of river pollution. Biomarkers. 1997;2(4):247-252.

42. Hussain S, Rodgers D, Duhart HA, et al. Mercuric chloride-induced reactive oxygen species and its effect on antioxidant enzymes in different regions of rat brain. J Environ Sci Health. 1997;32(3):395409 .

43. Erusan Bharathi, Ganesan Jagadeesan, Murugan Vijayakumar. Hepatoameliorative effect of hesperidin and ellagic on mercuric chloride intoxicated rats. Biomedicine \& Aging Pathology. 2014;4(1):17-21.

44. Jihen EH, Imed M, Fatima H, et al. Protective effects of selenium (Se) and zinc $(\mathrm{Zn})$ on cadmium $(\mathrm{Cd})$ toxicity in the liver of the rat: effects on the oxidative stress. Ecotox Environ Saf. 2009;72(5):1559-1564.

45. Alam MS, Kaur G, Jabbar Z, et al. Eruca sativa seeds possess antioxidant activity and exert a protective effect on mercuric chloride induced renal toxicity. Food Chem Toxicol. 2007;45(6):910-920.

46. Bharathi E, Jagadeesan G, Manivasagam T. Influence of s-allyl cysteine against mercuric chloride induced nephrotoxicity in albino rats. $J$ Chem Pharm Res. 2012;4(3):1470-1474.

47. De CarvalhoI NC, Frydberg ML, Daniela Dimer L, et al. Evaluation of the genotoxicand antigenotoxic potential of Melissa officinalis in mice. Genet Mol Biol. 2011;34(2):290-297.

48. Yehia MA, El-Banna SG, Okab AB. Diazinon toxicity affects histophysiological and biochemical parameters in rabbits. Exp Toxicol Pathol. 2007;59(3-4):215-225.

49. Gokcimen A, Gulle K, Demirin H, et al. Effects of diazinon at different doses on rat liver and pancreas tissues. Pesticide Biochemistry and Physiology. 2007;87:103-108. 